\title{
Trends and estimates in prostate cancer incidence, mortality and prevalence in the Slovak Republic, 1968-2012
}

\author{
M. ONDRUSOVA ${ }^{1,2, *}$, L. MROZOVA ${ }^{3}$, D. ONDRUS ${ }^{4}$, B. MRINAKOVA ${ }^{5}$ \\ ${ }^{1}$ Cancer Research Institute, Slovak Academy of Sciences, Bratislava, Slovak Republic; ${ }^{2}$ St. Elizabeth University of Health and Social Sciences, Bratislava, \\ Slovak Republic; ${ }^{3}$ Caldera, Banska Bystrica, Slovak Republic; ${ }^{4} 1{ }^{\text {st }}$ Department of Oncology, Comenius University, Faculty of Medicine, St. Elisabeth \\ Cancer Institute, Bratislava, Slovak Republic; ${ }^{5}$ Department of Clinical Oncology, St. Elisabeth Cancer Institute, Bratislava, Slovak Republic
}

*Correspondence: martina.ondrusova@hotmail.com

Received October 15, 2012/ Accepted December 17, 2012

\begin{abstract}
Prostate cancer is the third most-common non-skin cancer and also the third leading cause of cancer death in the Slovak Republic in recent years. However, analysis of incidence and mortality long-term time-trends, on the basis of which the prevalence estimates could have been calculated, were not available. This paper analyses national trends in prostate cancer incidence and mortality from 1968 to 2007 by using the join-point regression to propose potential changes in health care. The authors noted a statistically significant increase in the values of incidence after 1999 and improvement in mortality after 1998. Using a mathematical modelation authors predicted the overall prostate cancer prevalence in the Slovak Republic to provide actual data for health management.
\end{abstract}

Key words: prostate cancer - epidemiology, incidence, mortality, prevalence

Prostate cancer is the second most frequent cause of cancer and the $6^{\text {th }}$ leading cause of cancer death in males worldwide, excluding non-melanoma skin cancer [1]. Starting from the second half of 1980s [2], opportunistic screening by means of PSA testing caused a rapid rise in incidence rates and prostate cancer has become the third most common non-skin cancer in the Slovak Republic (SR), representing $10.2 \%$ from all malignancies in males [3]. Variations in prostate cancer incidence are mainly caused by the differences in detection practices, lifestyle and genetic factors, while mortality rates reflect differences in treatment as well as underlying risk [4]. In the SR, prostate cancer is the third leading cause of cancer death among males, representing $7.2 \%$ of all cancer mortality in males in 2007. Due to its high relative survival rates and low fatality, prostate cancer remains the most prevalent cancer in males. However, the overall prevalence data is not often available from local registries, despite the fact that they are essential for health and drug policy planning. This paper analyses and interprets long-term prostate cancer incidence and mortality trends in the SR between 1968-2007 by using join-point regression to propose potential changes in health care, mainly PSA testing and treatment management. We noted a statistically significant increase in the values of incidence after 1999 by using join- point regression analysis and an improvement in the indicators of mortality after 1998, influenced by better and more effective diagnosis and treatment. Using a mathematical modelation the work predicts probable development of the incidence and mortality trends in the following years 2008-2012 and estimates the overall prostate cancer prevalence in the SR.

\section{Material and methods}

Data sources. All the cases of prostate cancer registered in the National Cancer Registry (NCR) SR between1968-2007 were identified [3, 5-8]. NCR SR is a population-based cancer registry, which covers the whole SR (approximately 5.5 million people) and relies on mandatory cancer notifications from health care sources and death certificates from the Statistical Office of the SR. Information on mid-year population and mortality data were obtained from the Statistical Office of the SR as the "Official Mortality Data", with no ability to cite the resources. Incidence, mortality and prevalence data from other countries that are compared with the situation in the SR, were obtained from the GLOBOCAN 2008 cancer database and the European Cancer Observatory database of the IARC WHO $[1,9]$. 
Statistical analysis. Age-standardized incidence and mortality rates (ASR) in the SR were calculated, using direct standardization method and World (W) standard population as a reference [10]. The trends in incidence and mortality have been extracted separately in the time period 1968-2007 and were carried out by the join-point regression analysis using the software Join-point Regression Program, Version 3.5.3 [11]. The analysis included the logarithmic transformation of the rates, standard error, maximum number of four joinpoints, and minimum of four years between two join-points. All other program parameters were set to default values. The aim of the approach is to identify possible join-points where a significant change in the trends occurs. The method identifies join-points based on regression models with 0-4 join-points. The final selected model was the most parsimonious of these, with the estimated annual percentage change (EAPC) based on the trend within each segment [12]. To quantify the trend over a fixed period, the average annual percentage change (AAPC) was calculated. The AAPC is computed as a geometric weighted average of the EAPC trend analysis, with the weights equal to the lengths of each segment during the pre-specified fixed interval. The trends are presented with a corresponding $95 \%$ Confidence Intervals (CI) and p-value with the null hypothesis being constant with time.

The prevalence model calculates with the absolute number of prostate cancer specific mortality in the individual 5-year age groups, which was adjusted for a specific age group. For a more conservative estimate, the incidence and mortality prediction in y.2008-2012 was performed by the linear join-point analysis through crude incidence and mortality data, adjusted to absolute numbers of prevalence (mortality) after 5-year age groups and ASR-W. The overall prevalence is calculated as a sum of prevalence data of the individual age groups, prevalence for the defined age group is calculated by the formula:

$P_{n, y}=P_{n-1, y-1}\left(1-k g_{n, y}\right)+i_{n, y}-m_{n, y}$

is the incidence in year,"n" and age group " $\mathrm{y}^{\prime \prime}$

$\mathrm{m}_{\mathrm{n}, \mathrm{y}}^{\mathrm{n}, \mathrm{y}}$ is the mortality in year " $\mathrm{n}$ “ " and age group ", ${ }^{\text {“ }}$

$\mathrm{q}_{\mathrm{n}, \mathrm{y}}$ is the general presumption/probability of death in year "n" " and defined age group "y"

$\mathrm{k}=0.80$, while $20 \%$ of population dies due to malignant neoplasms in Slovakia

The model of general prevalence anticipates, that the prevalence at the beginning of a monitored period in which the modelation begins, is $\mathrm{L}$ - fold of the incidence value in the first given year of modelation. The L- coefficient was determined individually, interactively as a consistent estimate of the ratio of anticipated prevalence and incidence.

\section{Results}

Age-standardized (ASR-W) incidence rate between the first (1968) and last (2007) registered year increased by $205.7 \%$, from ASR-W 14.6/100,000 (95\% CI \pm 1.577 ) to 44.6/100,000 (95\% CI \pm 2.256 ) (Fig. 1). Incidence rates in males increased over the entire period, with the best fitting model having a joinpoint in 1999, resulting in two separate trends: slower increase of incidence with EAPC $2.4 \%$ (CI $95 \%$ 2.1-2.7, p<0.0001) was registered in 1968-1999 and significantly faster increase of incidence with EAPC $5.8 \%$ (CI 95\% 3.3 - 8.4, p<0.0001) was registered between 1999-2007, while the shift of the increment of incidence in y. 1999 for the value of 3.4\% is also statistically significant $(\mathrm{p}=0.009)$. The averaged annual percentage change (AAPC) of modelled data of incidence from fixed time-period 1968-2007 was $3.1 \%$. Based on the outcome of the join-point analysis the expectation of the newly diagnosed prostate cancer in the y. 2012 are 2436 cases, i.e. ASR-W 59.3/100,000 (95 \% $\mathrm{CI} \pm 2.393$ ) (Fig. 2).

The age-specific incidence of prostate cancer in the analysed period has a sharp increasing tendency from age group 50-54y., while up until the average of years 1993-1997 it culminated in 80-84 year old men with subsequent but very modest decrease in incidence of the disease in the eldest age group ( $85 \mathrm{y.}+)$. In recent periods (in average y. 1998-2002 and 2003-2007) the age-specific incidence has an increasing tendency through the eldest age groups ( $85 \mathrm{y} .+$ )

Age-standardized mortality rates between 1968-2007 increased by just $85.4 \%$ (compared to $205.7 \%$ increase in incidence rates), from ASR-W 7.2/100,000 (95\% CI \pm 1.130$)$ to ASR-W 13.4/100,000 (95\% CI \pm 1.221 ) (Fig. 1). Join-point analysis identified three join-points, in 1977, 1993 and 1998, with consequent four trends. The period 1968-1977 was characterized by significant increasing tendency in mortality with EAPC $3.3 \%$ (95 \% CI 1.8-4.9, $\mathrm{p}=0.0002)$, in the period 1977-1993 the mortality had slower increasing tendency with EAPC $1.1 \%$ (95 \% CI 0.4-1.8, p=0.004), consequently after y.1998 a marked increase in mortality occurred with EAPC $6.4 \%$ (95 \% CI 0.9-12.1, p=0.022) and only since the y.1998 has the mortality in the SR stabilized tendency, characterized by non-significant decrease of EAPC - $1.4 \%$ (95 \% CI -2.9-0.1, $\mathrm{p}=0.070$ ). The AAPC of modelled data on mortality from a fixed time-period 1968-2007 was $1.7 \%$. Based on the outcomes of the join-point analysis the estimated death count for the prostate cancer in y.2012 in the SR represents 554 cases, i.e. ASR-W mortality 12.8/100,000 (CI 95\% \pm 1.092 ) (Fig. 3).

The age-specific mortality has had a markedly increasing tendency in the analysed period from the age group 55-59 y., whereas it has a long term culmination in the eldest age groups $85 \mathrm{y} .+$. In the last analysed period (average of the years 20032007) a modest decrease of the death count was recorded in all age groups, in comparison with previous periods.

Prostate cancer represents a highly prevalent malignancy, with an estimated count of 12.528 overall registered cases in the y.2012 (Fig. 4).

\section{Discussion}

When compared to GLOBOCAN 2008, the SR is a country with moderate prostate cancer incidence rates in the context with the Central and Eastern European countries. With ASR- 


\begin{tabular}{|c|c|c|c|c|c|c|}
\hline year & $\begin{array}{l}\text { Abs.No. of } \\
\text { diagnosis }\end{array}$ & $\begin{array}{c}\text { CR incidence } \\
/ 100,000\end{array}$ & $\begin{array}{c}\text { ASR-W } \\
\text { incidence } \\
/ 100,000\end{array}$ & $\begin{array}{l}\text { Abs.No. of } \\
\text { deaths }\end{array}$ & $\begin{array}{c}\text { CR mortality } \\
/ 100,000\end{array}$ & $\begin{array}{c}\text { ASR-W } \\
\text { mortality } \\
/ 100,000\end{array}$ \\
\hline 1968 & 345 & 305,2 & 14,6 & 168 & 208,8 & 7,2 \\
\hline 1969 & 328 & 299,2 & 13,4 & 177 & 204,7 & 7,4 \\
\hline 1970 & 359 & 355,2 & 14,6 & 184 & 226,1 & 7,5 \\
\hline 1971 & 354 & 341,1 & 14,3 & 196 & 204,6 & 8,0 \\
\hline 1972 & 341 & 234,2 & 13,1 & 196 & 117,1 & 7,4 \\
\hline 1973 & 346 & 346,1 & 13,3 & 196 & 214,2 & 7,6 \\
\hline 1974 & 402 & 277,0 & 14,8 & 249 & 228,1 & 9,3 \\
\hline 1975 & 444 & 418,6 & 16,3 & 247 & 273,7 & 9,0 \\
\hline 1976 & 460 & 428,1 & 16,6 & 255 & 317,1 & 9,4 \\
\hline 1977 & 499 & 282,1 & 17,2 & 264 & 250,7 & 9,3 \\
\hline 1978 & 375 & 262,5 & 13,0 & 270 & 277,9 & 9,6 \\
\hline 1979 & 413 & 252,7 & 14,5 & 292 & 341,9 & 10,2 \\
\hline 1980 & 448 & 169,3 & 14,5 & 279 & 211,7 & 9,2 \\
\hline 1981 & 555 & 250,0 & 18,4 & 311 & 315,7 & 10,3 \\
\hline 1982 & 562 & 238,2 & 18,3 & 328 & 238,2 & 10,4 \\
\hline 1983 & 579 & 252,7 & 18,8 & 285 & 216,6 & 9,3 \\
\hline 1984 & 623 & 298,0 & 20,2 & 335 & 171,9 & 10,7 \\
\hline 1985 & 589 & 320,4 & 19,1 & 325 & 181,5 & 10,0 \\
\hline 1986 & 621 & 318,8 & 19,8 & 332 & 226,2 & 10,5 \\
\hline 1987 & 648 & 265,9 & 21,1 & 301 & 177,2 & 9,3 \\
\hline 1988 & 650 & 336,4 & 20,8 & 341 & 299,0 & 10,8 \\
\hline 1989 & 683 & 294,6 & 21,7 & 382 & 339,2 & 11,7 \\
\hline 1990 & 712 & 369,2 & 22,6 & 343 & 214,6 & 10,6 \\
\hline 1991 & 706 & 318,2 & 22,5 & 386 & 411,8 & 12,2 \\
\hline 1992 & 704 & 259,6 & 20,9 & 366 & 232,3 & 10,6 \\
\hline 1993 & 753 & 346,9 & 22,3 & 395 & 274,9 & 11,3 \\
\hline 1994 & 725 & 410,6 & 22,8 & 371 & 458,9 & 11,8 \\
\hline 1995 & 756 & 467,0 & 23,9 & 416 & 405,8 & 12,7 \\
\hline 1996 & 833 & 451,8 & 26,0 & 447 & 303,7 & 13,6 \\
\hline 1997 & 912 & 506,8 & 28,2 & 459 & 465,1 & 13,9 \\
\hline 1998 & 938 & 584,1 & 28,5 & 522 & 597,4 & 15,4 \\
\hline 1999 & 861 & 569,7 & 26,1 & 541 & 512,7 & 15,7 \\
\hline 2000 & 965 & 607,9 & 28,7 & 537 & 670,6 & 15,6 \\
\hline 2001 & 1028 & 733,7 & 31,0 & 488 & 592,9 & 14,6 \\
\hline 2002 & 1029 & 521,6 & 30,7 & 474 & 609,9 & 13,9 \\
\hline 2003 & 1130 & 554,1 & 33,9 & 471 & 448,6 & 13,6 \\
\hline 2004 & 1220 & 687,3 & 36,0 & 481 & 556,8 & 13,6 \\
\hline 2005 & 1264 & 637,1 & 36,2 & 541 & 483,9 & 14,9 \\
\hline 2006 & 1355 & 551,1 & 39,1 & 501 & 469,2 & 14,0 \\
\hline 2007 & 1585 & 727,9 & 44,6 & 498 & 530,6 & 13,4 \\
\hline
\end{tabular}

Figure 1. Absolute numbers (Abs. No.) of the prostate cancer occurrence and deaths, crude rates (CR) and standardized rates (to the World standard population-ASR-W) of incidence and mortality in the Slovak Republic according to the National Cancer Registry data 


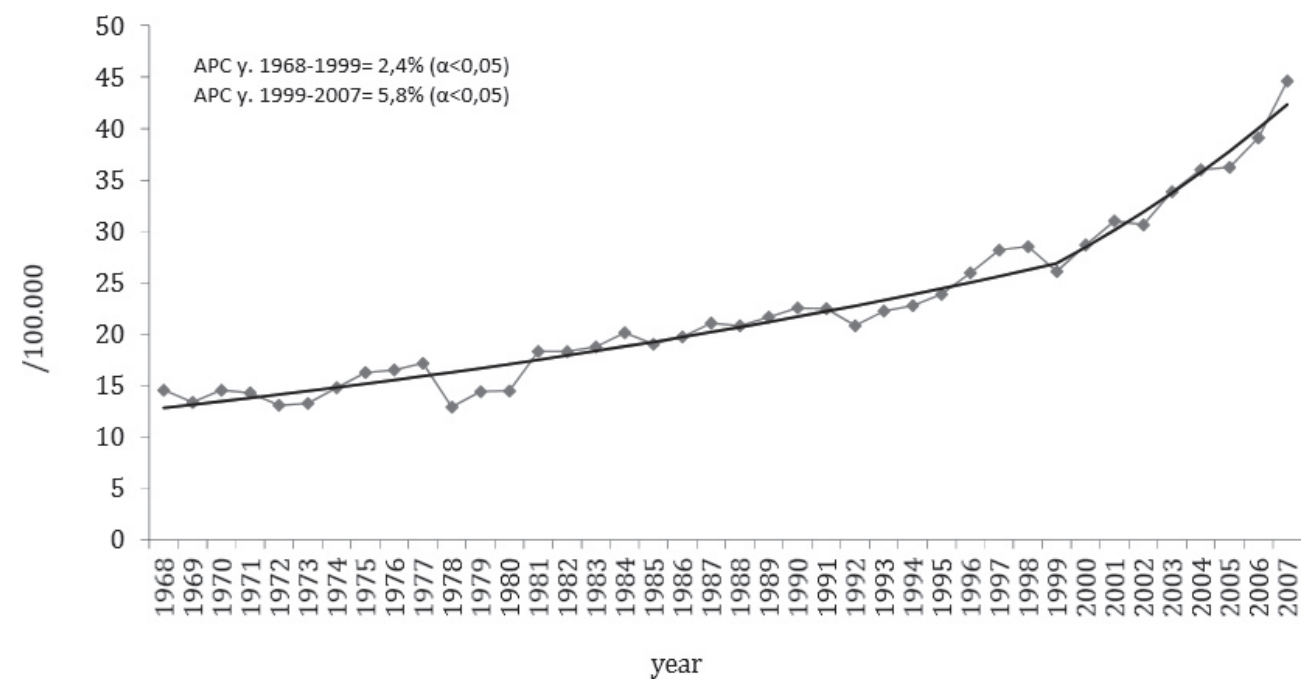

Figure 2. Time-trends of the age-standardized (to the World standard population - ASR-W) prostate cancer incidence and the joint-point regression in in the Slovak Republic, y.1968-2007. (APC=annual percentage change).

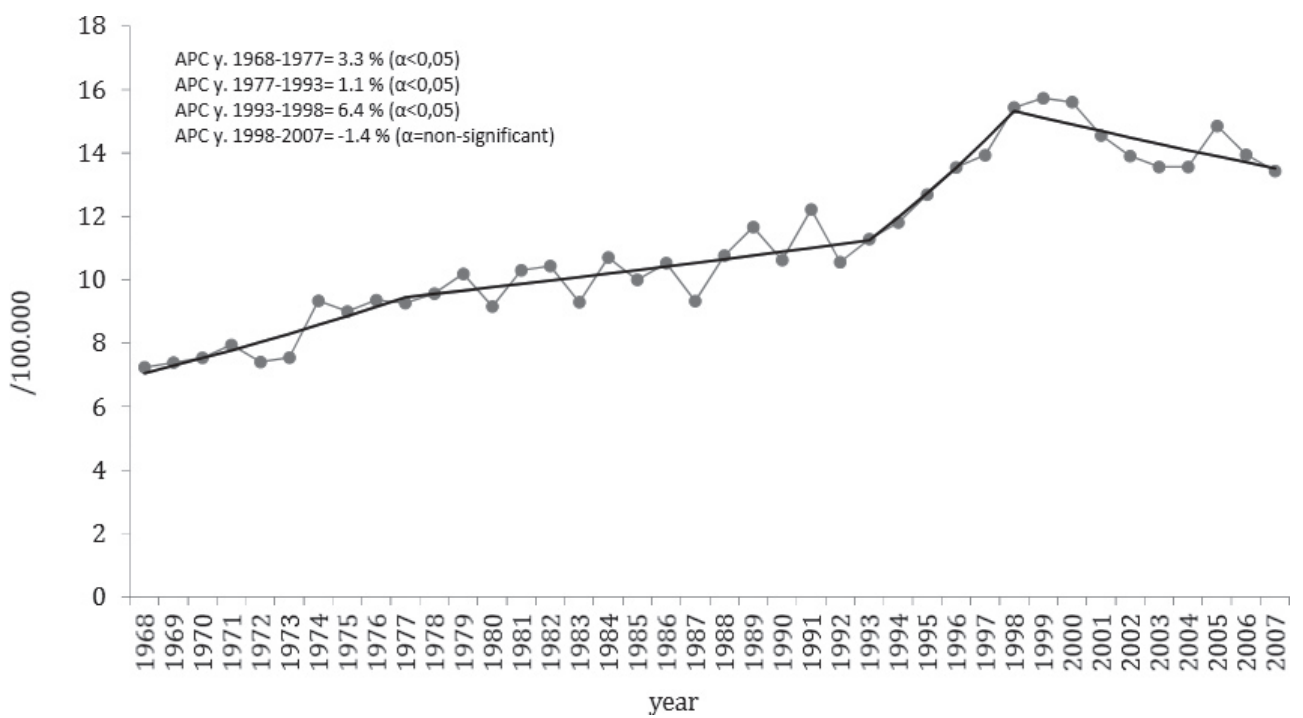

Figure 3. Time-trends of the age-standardized (to the World standard population - ASR-W) prostate cancer mortality and the joint-point regression in in the Slovak Republic, 1968-2007. (APC=annual percentage change).

$\mathrm{W}$ incidence rates it ranked 61st worldwide and 27th of 40 European countries $[1,2]$.

The incidence of prostate cancer varies greatly in individual geographic regions and countries of the world: the highest ASR$\mathrm{W}$ incidence rates are observed in the USA (its rates vary across the USA) and in New Zealand, thanks mostly to the screening examination $[1,13]$. The lowest incidence of prostate cancer is reported in several countries of South-East Asia [1, 14]. Many of the countries have experienced an increase in prostate cancer incidence $[15,16]$. The factor influencing the geographic distribution of prostate cancer is a variable degree of the utilization of the PSA exam and the capability to diagnose latent cancer [17, $18]$. In the SR, PSA testing was introduced during the second half of the 1980s [2, 19], wider acceptance of PSA testing and improved prostate biopsy techniques were applied subsequently, which reflected in changes in quickness of the incidence increase in $\mathrm{y} .1999$ by $+3.4 \%(\mathrm{p}=0.05)$, while EAPC since the $\mathrm{y} .1999$ was in the SR $+5.8 \%$. Similar changes are described also in some other European countries, incidence rates have sharply increased e.g. in Denmark (in 1995, EAPC was 7.2 \%), Finland (in 1990, EAPC 9.3 \%), Latvia (in 1994, EAPC 11 \%), Sweden (in 1996, EAPC 6.9 \%), Czech Republic (in 1990, EAPC $6.9 \%$ ) 


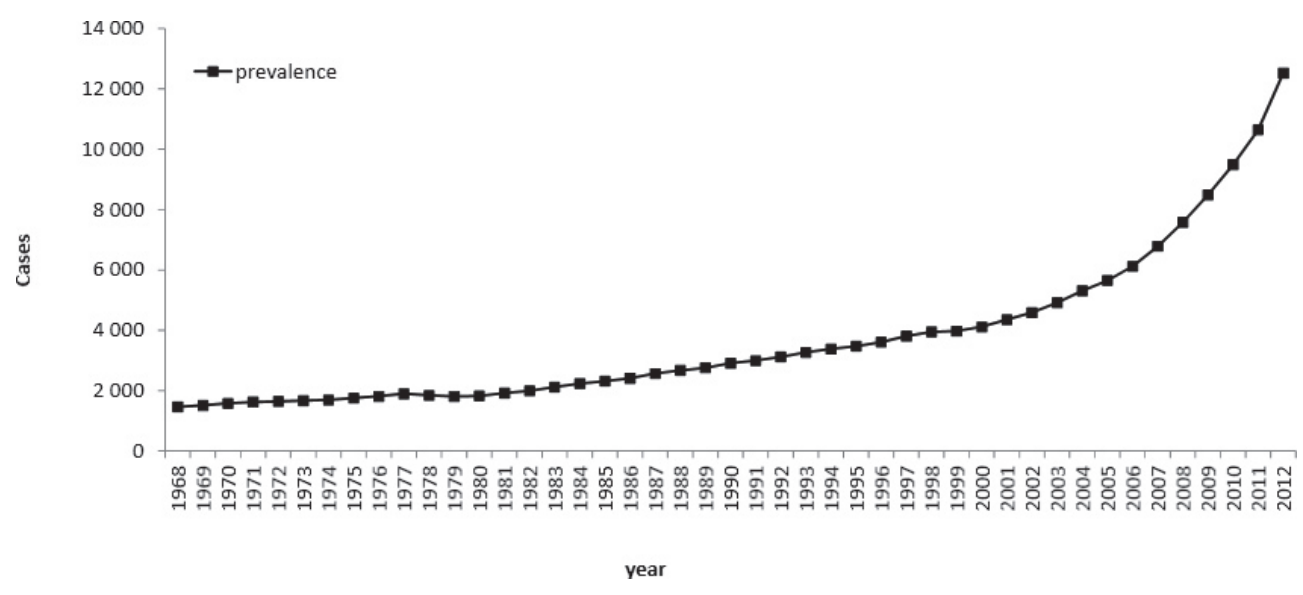

Figure 4. Estimates of prostate cancer prevalence (cases) in the Slovak Republic up to y. 2012.

and Croatia (in 1997, EAPC $12.9 \%$ ) [4, 18]. Since the highest incidence rates are usually reported from the countries with high health care expenditure, the changes in incidence evolution are influenced by increased public awareness, PSA testing and higher detection of latent cancer in prostate surgery [16]. It remains unclear as to what extent the increasing trend in incidence indicates true risk or if it represents increased detection of latent disease [15]. However it is obvious, that in some countries with wide application of the PSA testing (for example Finland, Sweden and the Netherlands) [15], resp. in countries with established active screening based on PSA (from European countries only in Lithuania) [20], the decline of prostate cancer incidence has been observed in recent years, which is caused by detection of the majority of the asymptomatic cases in population. This trend was not observed until the end of the y.2007 in the SR, indirectly it confirms the absence of broad PSA testing (also in asymptomatic population).

According to the join-point analysis, the increase of incidence in the SR allows us to predict the prospective evolution of disease. In y. 2012 the estimation of newly diagnosed cases is 2436 , in the y.2008 the estimate represents 1743 cases. With reference to present available estimates [1,9], our prediction of the incidence in y.2008 is higher, which may be influenced by the fact that our model calculates also with prostate cancer cases registered in the SR in latter years 2006 and 2007 (in comparison with y.2005 in IARC WHO), whereby in these specific years a marked increase in incidence had happened which influenced the whole model consequently. On the other hand, our prevalence estimates for the y.2008 are 11\% lower than the prediction of IARC WHO $[1,9]$, which may be influenced by the calculation with general and specific mortality in our model, while other models [9] preferably use specific survival of patients according to 5year age groups to estimate the prevalence. The last published prostate cancer survival data in the SR according to 5-year age group is in cohort y. 1990-1994 [21], which is not actual already, this confirms also the alteration in overall survival for prostate cancer published from national registries (64.6\% in cohort y. 2000-2004 in comparison with $42.8 \%$ in cohort y. 1980-1984) [8]. The interpolation of recent survival data from the neighbouring countries [21] wouldn't necessarily reflect reality in the SR. The reason for our choice for the prevalence model was the necessity of prediction of the evolution of the overall prevalence (likewise also incidence and mortality) since present, i.e. not only to estimate the 5-year prevalence [9].

The SR is a country with lower prostate cancer mortality rates according to Globocan estimates in 2008 [1,2]. With ASR-W mortality rates it ranked $81^{\text {st }}$ worldwide and $18^{\text {th }}$ of 40 European countries. Over the past decade a marked decline in prostate cancer mortality was observed in many countries [4, $22]$ in Europe predominantly since the mid-1990's and particularly in higher-resource countries of Western Europe and Nordic countries. Prostate cancer mortality rates decreased from EAPC - $2.3 \%$ in Germany and the Netherlands to $-4 \%$ in Austria [4]. Mortality increased in several Eastern European countries, except the Czech Republic and Hungary [4, 15]. However, a little relation between the increasing incidence and decreasing mortality appears in the recent past, consistent with the effect of over-diagnosis or detection of indolent tumors via PSA testing [15]. The stabilization in prostate cancer mortality trends by non-significant declining EAPC $-1.4 \%$, which was found out in the SR in recent years, might be attributed to PSA testing, whereas while this decrease of mortality didn't meet statistical significance, it is assumed that PSA testing isn't commonly used outside the urological practice. As the change in mortality started in 1998, the intervention most probably took place around 1992 (assuming approximately 7 years delaytime before an intervention reflects its effect on mortality rates [23] and the increase of use of the DRE, TRUS, needle biopsy, as well as better treatment modalities might also have had an influence) $[4,15]$. Still not favourable evolution of mortality is also affected by the delayed accessibility to modern treatment in comparison with western countries, which is often described in various different malignancies. Despite several studies evaluating the effect of PSA testing on prostate-cancer 
mortality rates have shown conflicting results [24, 25], the recent analyses of Schröder et al. [25] on ERCP study population found out a significant reduction of prostate cancer specific mortality, however lesser in all-cause mortality.

Although the decrease in incidence and stabilization in overall mortality is recorded in the SR in recent years (without the ability of identification prostate-specific mortality), the progress of these changes suggests that PSA testing does not have a broad character in the content of new case detection or examination outside the urological practice. The legal obligation to declare the absolute numbers of overall prevalence of prostate cancer for the purposes of health care planning lead to the invention of a mathematical model adjusted for the Slovak population, which enables actual prevalence, incidence and mortality predictions into the current year.

\section{References}

[1] FERLAY J, SHIN HR, BRAY F, FORMAN D, MATHERS C et al. GLOBOCAN 2008, Cancer incidence and mortality worldwide: IARC CancerBase No. 10 [Internet]. Lyon: IARC; 2010. Available from: http://globocan.iarc.fr/

[2] ONDRUSOVA M, ONDRUS D, KARABINOS J, MUZIK J, KLIMENT J et al. Trends in prostate cancer incidence and mortality before and after the introduction of PSA testing in the Slovak and Czech Republics. Tumori 2011; 97: 149-155.

[3] SAFAEI-DIBA CH, PLESKO I, HLAVA P (eds.). Cancer incidence in the Slovak Republic 2007. Bratislava: NCR SR, NHIC, 2012.

[4] CENTER MM, JEMAL A, LORTET-TIEULENT J, WARD E, FERLAY J et al. International variation in prostate cancer incidence and mortality rates. Eur Urol 2012; 61: 1079-1092. http://dx.doi.org/10.1016/j.eururo.2012.02.054

[5] ONDRUSOVA M, PLESKO I, SAFAEI-DIBA C, OBSITNIKOVA A, STEFANAKOVA D et al. Comprehensive analysis of incidence and mortality of malignant tumours in the Slovak Republic [online]. Bratislava: NCR SR, NHIC, 2007. http:// www.nor-sk.org/.

[6] SAFAEI-DIBA C, PLESKO I, FRINDTOVA V, KOPECKA I, KRAKOVSKA B et al. Cancer incidence in the Slovak Republic 2004. Bratislava: NCR SR, NHIC, 2008.

[7] SAFAEI-DIBA C, PLESKO I, OBSITNIKOVA A, DIENEROVA M, KALMANCOKOVA A et al. Cancer incidence in the Slovak Republic 2005. Bratislava: NCR SR, NHIC, 2009.

[8] SAFAEI-DIBA CH, PLESKO I, HLAVA P (eds.). Cancer incidence in the Slovak Republic 2006. Bratislava: NCR SR, NHIC, 2010.

[9] STELIAROVA-FOUCHER E, O`CALLAGHAN M, FERLAY J, MASUYER E, COMBER H et al. European cancer observatory: Cancer incidence, mortality, prevalence and survival in Europe. Version 1.0 (September 2012) European Network of Cancer Registries, Lyon, IARC, Available from http://eco.iarc.fr.

[10] BRAY F, GUILLOUX A, SANKILA R, PARKIN DM. Practical implications of imposing a new world standard population. Cancer Causes Control 2002; 13: 175-182. http://dx.doi. org/10.1023/A:1014344519276
[11] National Cancer Institute, Surveillance research: http://surveillance.cancer.gov/joinpoint/

[12] KIM HJ, FAY MP, FEUER EJ, MIDTHUNE DN. Permutation tests for joinpoint regression with applications to cancer rates. Stat Med 2000; 16: 335-351.

[13] CURADO MP, EDWARDS B, SHIN HR, FERLAY J, HEANUE $\mathrm{M}$ et al. (eds.) Cancer incidence in five continents, Vol. IX, IARC Scient Publ. No. 160. Lyon 2007.

[14] FERLAY J, BRAY F, PISANI P, PARKIN DM. Globocan 2002: Cancer incidence, mortality and prevalence worldwide. IARC Cancer Base No. 5, IARC Press, Lyon 2004. Available at: http://www-dep.iarc.fr/

[15] BRAY F, LORTET-TIEULENT J, FERLAY J, FORMAN D, AUVINEN A. Prostate cancer incidence and mortality trends in 37 European countries: an overview. Eur J Cancer 2010; 46: 3040-3052. http://dx.doi.org/10.1016/j.ejca.2010.09.013

[16] KULIS T, KRHEN I, KASTELAN Z, ZNAOR A. Trends in prostate cancer incidence and mortality in Croatia, 1988-2008. Croat Med J 2012; 53: 109-114. http://dx.doi.org/10.3325/ cmi.2012.53.109

[17] BAADE PD, YOULDEN DR, KRNJACKI LJ. International epidemiology of prostate cancer: Geographical distribution and secular trends. Mol Nutr Food Res 2009; 53: 171-184. http://dx.doi.org/10.1002/mnfr.200700511

[18] HAAS GP, DELONGCHAMPS, N, BRAWLEY OW, WANG CY, DE LA ROSA G. The worldwide epidemiology of prostate cancer: perspectives from autopsy studies. Can J Urol 2008; 15: 3866-3871.

[19] KAUSITZ J. Possibilities in using radioimmunoassay of tumor markers in diagnosis of carcinomas of the testes and prostate. Bratisl Med J 1988; 89: 715-724 (in Slovak).

[20] SMAILYTE G, ALEKNAVICIENE B. Incidence of prostate cancer in Lithuania after introduction of the Early Prostate Detection Programme. Public Health 2012; 126: 1075-1077. http://dx.doi.org/10.1016/j.puhe.2012.01.016

[21] BERRINO F, DE ANGELIS R, SANT M, ROSSO S, BIELSKALASOTA M et al. Survival for eight major cancers and all cancers combined for European adults diagnosed in 1995-99: results of the EUROCARE-4 study. Lancet Oncol. 2007; 8: 773-783. http://dx.doi.org/10.1016/S1470-2045(07)70245$\underline{0}$

[22] VAN LEEUWEN PJ, CONNOLLY D, GAVIN A, ROOBOL MJ, BLACK A et al. Prostate cancer mortality in screen and clinically detected prostate cancer: Estimating the screening benefit. Eur J Cancer 2010; 46: 377-383. http://dx.doi. org/10.1016/j.ejca.2009.09.008

[23] CREMERS RGHM, KARIM-KOS HE, HOUTERMAN S, VERHOEVEN RHA, SCHRÖDER FH et al. Prostate cancer: Trends in incidence, survival and mortality in the Netherlands, 1989-2006. Eur J Cancer 2010; 46: 2077-2087. http://dx.doi. org/10.1016/j.ejca.2010.03.040

[24] BRAWLEY OW, ANKERST DP, THOMPSON IM. Screening for prostate cancer. CA-A Cancer J Clin 2009; 59: 264-273. http://dx.doi.org/10.3322/caac.20026

[25] SCHRÖDER FH, HUGOSSON J, ROOBOL MJ, TAMMELA TLJ, CIATTO $S$ et al. Prostate-cancer mortality at 11 years of follow-up. N Engl J Med 2012; 266: 981-990. 